\title{
SEDENTARY BEHAVIOR AND CARDIOVASCULAR RISK IN CHILDREN: A SYSTEMATIC REVIEW
}

\author{
COMPORTAMENTO SEDENTÁRIO ERISCO CARDIOVASCULAREM CRIANÇAS: UMA REVISÃO SISTEMÁTICA \\ COMPORTAMIENTO SEDENTARIO Y RIESGO CARDIOVASCULAR EN NIÑOS: UNA REVISIÓN SISTEMÁTICA
}

Systematic Review Article

ARTIGO DE REVISÃO SISTEMÁTICA

ARTíCULO de REVISIÓN SISTEMÁTICA

Karina Lúcia Ribeiro Canabrava ${ }^{1,2}$ (Physical Education Professional) Paulo Roberto dos Santos Amorim (Physical Education Professional) Valter Paulo Neves Miranda3,4 (Physical Education Professional)

Silvia Eloiza Priore ${ }^{4}$

(Nutritionist)

Sylvia do Carmo Castro

Franceschini ${ }^{4}$ (Nutritionist)

1. Universidade Federal de Minas Gerais, Health Sciences Graduate Program, Belo Horizonte, MG, Brazil. 2. Centro Federal de Educação Tecnológica de Minas Gerais, Contagem, MG, Brazil. 3. Universidade Federal de Viçosa, Department of Physical Education, Viçosa, MG, Brazil. 4. Universidade Federal de Viçosa, Department of Nutrition and Health, Viçosa, MG, Brazil.

\section{Correspondence:}

Karina Lúcia Ribeiro Canabrava. Centro Federal de Educação Tecnológica de Minas Gerais, Contagem, MG, Brazil. 32146054. karinacanabrava@yahoo.com.br

\begin{abstract}
In recognition of the increasing time spent in sedentary activities in modern life, an emerging area of study linking sedentary time to health has highlighted its role in the development of chronic diseases. Therefore, the objective of this systematic review was to investigate the indicators and characteristics of sedentary behavior associated with cardiovascular risk factors in children and adolescents. The databases SciVerse Scopus, MEDLINE /PubMed and LILACS were selected as a source of reference, using the associated terms "sedentary lifestyle" or "sedentary behavior" or "sedentary" AND "cardiovascular diseases" AND "child or adolescent" to identify studies published from January 2006 to March 2019. The methodological quality of the studies was evaluated and a score was assigned. Fifty articles were included in this review at the end. Extensive sedentary time, especially greater screen and TV exposure time, were associated with cardiovascular risk factors. In addition, the accumulation of prolonged sedentary bouts with few breaks in sedentary time tended to compromise the cardiometabolic profile. These findings highlight the importance of differentiating and considering these various indicators and characteristics of sedentary behavior. Further studies are needed to elucidate the multiple and overlapping facets of sedentary behavior and their relationship with health, and to encourage the development of evidence-based recommendations for this population. Level of Evidence I; Systematic Review of Level I Studies.
\end{abstract}

Keywords: Sedentary behavior; Cardiovascular diseases; Child; Adolescent; Systematic review.

\section{RESUMO}

Em reconhecimento ao crescente tempo gasto em atividades sedentárias na vida moderna, uma emergente área de estudo tem relacionado o tempo sedentário à saúde e destacado seu papel no surgimento de doenças crônicas. Assim, o objetivo desta revisão sistemática foi investigar os indicadores e as características do comportamento sedentário associados aos fatores de risco cardiovascular em crianças e adolescentes. As bases de dados SciVerse Scopus, MEDLINE /PubMed e LILACS foram consultadas utilizando a combinação dos termos "sedentary lifestyle" OR "sedentary behaviour" OR sedentary AND "cardiovascular diseases" AND child or adolescent, para identificar estudos publicados de janeiro de 2006 a março de 2019. A análise da qualidade metodológica dos estudos foi realizada, e um escore foi atribuído. Ao final, 50 artigos foram incluídos nesta revisão. O elevado tempo sedentário e, principalmente, a maior exposição ao tempo de tela e televisão, foram associados a fatores de risco cardiovascular. Além disso, o acúmulo de prolongadas sessões e poucas interrupções no tempo sedentário parecem comprometer o perfil cardiometabólico. Destaca-se a importância em diferenciar e considerar estes diversos indicadores e características do comportamento sedentário. Estudos devem ser conduzidos para compreensão das múltiplas e superpostas facetas do comportamento sedentário e relações com a saúde, favorecendo o desenvolvimento de recomendações baseadas em evidências para essa população. Nível de evidência l; Revisão sistemática de estudos de nível I.

Descritores: Comportamento sedentário; Doenças cardiovasculares; Criança; Adolescente; Revisão sistemática.

\section{RESUMEN}

En reconocimiento al creciente tiempo invertido en actividades sedentarias en la vida moderna, una emergente área de estudio ha relacionado el tiempo sedentario a la salud, destacando su papel en el surgimiento de enfermedades crónicas. Así, el objetivo de esta revisión sistemática fue investigar los indicadores y las características del comportamiento sedentario asociados a los factores de riesgo cardiovascular en niños y adolescentes. Las bases de datos SciVerse Scopus, MEDLINE /PUBMED y LILACS fueron consultadas utilizando la combinación de términos "sedentary lifestyle" OR "sedentary behavior" OR sedentary AND "cardiovascular diseases" AND child or adolescent para identificar estudios publicados entre enero de 2006 y marzo de 2019. Se realizó el análisis de la calidad metodológica de los estudios y fue atribuido un puntaje. Al final, 50 artículos fueron incluidos en esta revisión. El elevado tiempo sedentario y, principalmente, la mayor exposición al tiempo de exposición de pantalla y la televisión, fueron asociados a factores de riesgo cardiovascular. Además, la acumulación de prolongadas sesiones y pocas interrupciones en el tiempo sedentario parecen comprometer el perfil cardiometabólico. Se destaca la importancia de diferenciar y considerar estos diversos indicadores y características del comportamiento sedentario. Deben ser conducidos estudios para la comprensión de las múltiples y sobrepuestas facetas del sedentarismo y relaciones con la salud, favoreciendo el desarrollo de recomendaciones basadas en evidencias para esa población. Nivel de Evidencia l; Revisión sistemática de estudios de Nivel I.

Descriptores: Conducta sedentaria; Enfermedades cardiovasculares; Niño; Adolescente; Revisión sistemática. 


\section{INTRODUCTION}

Sedentary behavior, which is distinct from physical inactivity, is defined as activities performed in a sitting or reclining position that involve energy expenditure similar to the resting level $(\leq 1.5$ metabolic equivalent units), such as watching TV, using the computer, and motorized transportation usage. 1,2 Despite the apparent simplicity of the term, sedentary behavior is complex and not limited to a single component. ${ }^{1}$

Considering that increasing time is being spent on sedentary activities of modern life, an emerging area of studies relates sedentary time to health status and highlights its potential role in the development of chronic diseases. ${ }^{2}$ It has been suggested that prolonged sitting is associated with deleterious effects on cardiovascular and metabolic health, regardless of whether individuals meet the recommendations for daily physical activity. Therefore, it is considered a risk factor for adiposity and cardiovascular diseases, distinct from physical inactivity. ${ }^{3}$

Epidemiological studies among adults have demonstrated that sedentary time is associated with increased risk of cardiovascular morbidity and mortality, independent of moderate-to-vigorous physical activity. ${ }^{4}$ Specific behaviors have been assessed and it was found that individuals with high screen time, defined as the sum of time spent watching TV and using the computer or other screen devices, ${ }^{5}$ are at a greater risk of future cardiovascular events. ${ }^{4}$ In addition to total sedentary time, patterns of sedentary time accumulation have been evaluated; studies show that a reduction in prolonged sedentary bouts and increasing breaks in sedentary time are beneficially associated with health in the adult population. ${ }^{6}$

Among children and adolescents, screen time has also been associated with markers of cardiovascular disease. ${ }^{7,8}$ A review ${ }^{7}$ revealed that excessive TV time was associated with physical and psychosocial health and provided the evidence for the guidelines for limiting screen time. ${ }^{5}$ Regarding other aspects of sedentary behavior, the evidence is still limited because TV time has been the most commonly used indicator of sedentary behavior for the pediatric population.?

Thus, the growing interest of the pediatric research community in sedentary behavior has generated much discussion on the determinants of sedentary behavior and its impact on the health of children and adolescents. ${ }^{7,8}$ Different domains, indicators, and patterns of this health-compromising behavior have been addressed. ${ }^{8}$ Converging the evidence obtained thus far and indicating the observed gaps may facilitate the planning of future studies and development of evidence-based guidelines for this population. Therefore, the objective of the present systematic review was to determine the main indicators and patterns of sedentary behavior associated with risk factors for cardiovascular disease in children and adolescents.

\section{MATERIALS AND METHODS}

The review was conducted according to the criteria proposed for systematic reviews and meta-analyses (Preferred Reporting Items for Systematic Reviews and Meta-Analyses - PRISMA). ${ }^{9}$ The search was performed in the following electronic databases: SciVerse Scopus, MEDLINE/PUBMED (Medical Literature Analysis and Retrieval System Online), and Literatura Latino-Americana e do Caribe em Ciências da Saúde (LILACS). The following combinations of health terms and descriptors were used: ("sedentary lifestyle" or "sedentary behavior" or sedentary) AND ("cardiovascular diseases") AND (child or adolescent). In addition to the descriptors, the terms "sedentary behavior" and "sedentary" were included for widening the search and incorporating studies that might be within the scope of this review, because the term "estilo de vida sedentário" was included as a health descriptor (Medical Subject Headings, MeSH) only in 2010. Considering that
2006 was the year that marked the calling for research focusing on sedentary behavior, ${ }^{2}$ this review investigated studies published from January 1, 2006 to January 31, 2016. There was a subsequent update in the study and a new search was performed considering the period between February 1, 2016 and March 31, 2019. In the PUBMED search engine, the search filter of "age group" was applied and the search was restricted to studies involving participants aged between zero and 18 years. Additional records were obtained from the review of the reference lists of the articles analyzed for eligibility.

The following inclusion criteria were used: 1) studies that addressed the topic through analysis of the association between sedentary behavior and cardiovascular risk (CR) factors; 2) studies with samples comprising children and/or adolescents; 3) original articles; and, 4) articles published in English, Portuguese, or Spanish. All study designs were eligible.

To examine sedentary behavior, the review included studies that assessed exposure using subjective and/or objective methods. Several indicators and patterns of sedentary behavior were analyzed: total sedentary time (total daily volume of sedentary activities), bouts of sedentary time (continuous periods of sedentary time), breaks (interruptions in prolonged sedentary time), screen time (sum of time spent watching TV, playing video games (VG), using the computer, and/or other screen devices), time spent in watching TV or videos, playing VG, and using the computer.

To assess the relationship of sedentary behavior with CR factors, the review included studies assessing body adiposity, blood pressure (BP) levels, lipid profile, and insulin and glucose levels. Several studies used a CR score by combining risk factors, because this can provide a better measure of cardiovascular health than risk factors taken individually. Thus, studies evaluating $C R$ by combining two or more risk factors within the scope of this review were also included.

The following exclusion criteria were used: duplicate articles, review articles, editorials, and letters to the editor. In addition, studies addressing sedentary behavior as a synonym of physical inactivity and/or analyzing sedentary behavior in conjunction with physical inactivity were excluded.

After the initial search in the databases, the software for managing references, EndNote ${ }^{\circ}$, was used to import the selected records and exclude duplicate records. Subsequently, the titles and abstracts of the records retrieved were analyzed to select potentially relevant articles. When the title and abstract were insufficient, a full-text search was performed. After screening the records, copies of the full texts were obtained for eligibility analysis. The assessment of the methodological quality of the studies was performed using the Downs and Black scale ${ }^{10}$ adapted to include cross-sectional studies. The studies were assessed using 17 questions relating to external and internal validity, and scored according to the provided information, with the maximum score being 17 points. Article search, analysis, and inclusion were performed by one reviewer. A second reviewer was consulted when there were questions about including or excluding the article.

During data extraction, the results of studies exploring the associations between sedentary behavior and CR factors, in which the analyses considered physical activity as a potential confounding factor, were reported. When adjustment for physical activity was not performed, the results were presented, and the information was highlighted in the summary table.

\section{RESULTS}

The initial search (2006 - 2016) in the databases yielded 641 records, of which 387 were obtained from the Scopus database, 216 from MEDLINE/PUBMED, and 38 from LILACS. The updated search (2016 - 2019) yielded 172 records, of which 124 were obtained from Scopus, 38 from MEDLINE/PUBMED, and 10 from LILACS. Twelve records were added after 
a review of the reference lists of the articles analyzed for eligibility. Thus, a total of 825 records were identified. After excluding duplicates $(n=$ 213), 612 records were obtained for title and abstract screening. Of those screened, 546 records were excluded (irrelevant topics, adult population, and non-original articles). Therefore, 66 full-text articles were analyzed for eligibility. Then, 16 articles were excluded because they evaluated sedentary behavior combined with physical activity $(n=4)$, considered sedentary behavior as a synonym of physical inactivity $(n=1)$, analyzed the association of sedentary behavior and other risk factors that were not within the scope of this review $(n=6)$, sampled an adult population $(n=3)$, or reviewed articles exclusively $(n=2)$. Finally, 50 articles were included in the qualitative summary.11-60 (Figure 1)

All included studies had minimum and maximum methodological quality scores of 12 and 16 , respectively. Few studies utilized random (4\%) or longitudinal (10\%) design; the majority used a cross-sectional approach (86\%). A higher percentage of studies were conducted in the United States (22\%) and Canada (14\%). Most articles were published in 2013, 2014, and 2015. (Chart 1)

In terms of age groups, the studies analyzed children (16\%), adolescents (42\%), and children + adolescents (42\%). Sedentary behavior was most often evaluated using only questionnaires (62\%), with only $18 \%$ of studies using accelerometry, and 16\% using both approaches. Additionally, $4 \%$ of the studies used an exposure time assessment. The most frequently used indicators of sedentary behavior were screen time (46\%), TV time (44\%), and total sedentary time (44\%). (Chart 1)

\section{Sedentary Behavior and Body Adiposity}

As is shown in Table 1, most studies report a lack of association between total sedentary time and body mass index (BMI), 18,21,32,35,52,56 waist circumference (WC), 18,22,25,31,32,35,36,43,52,56,57 and body fat (BF). ${ }^{18,43,52,54,56}$

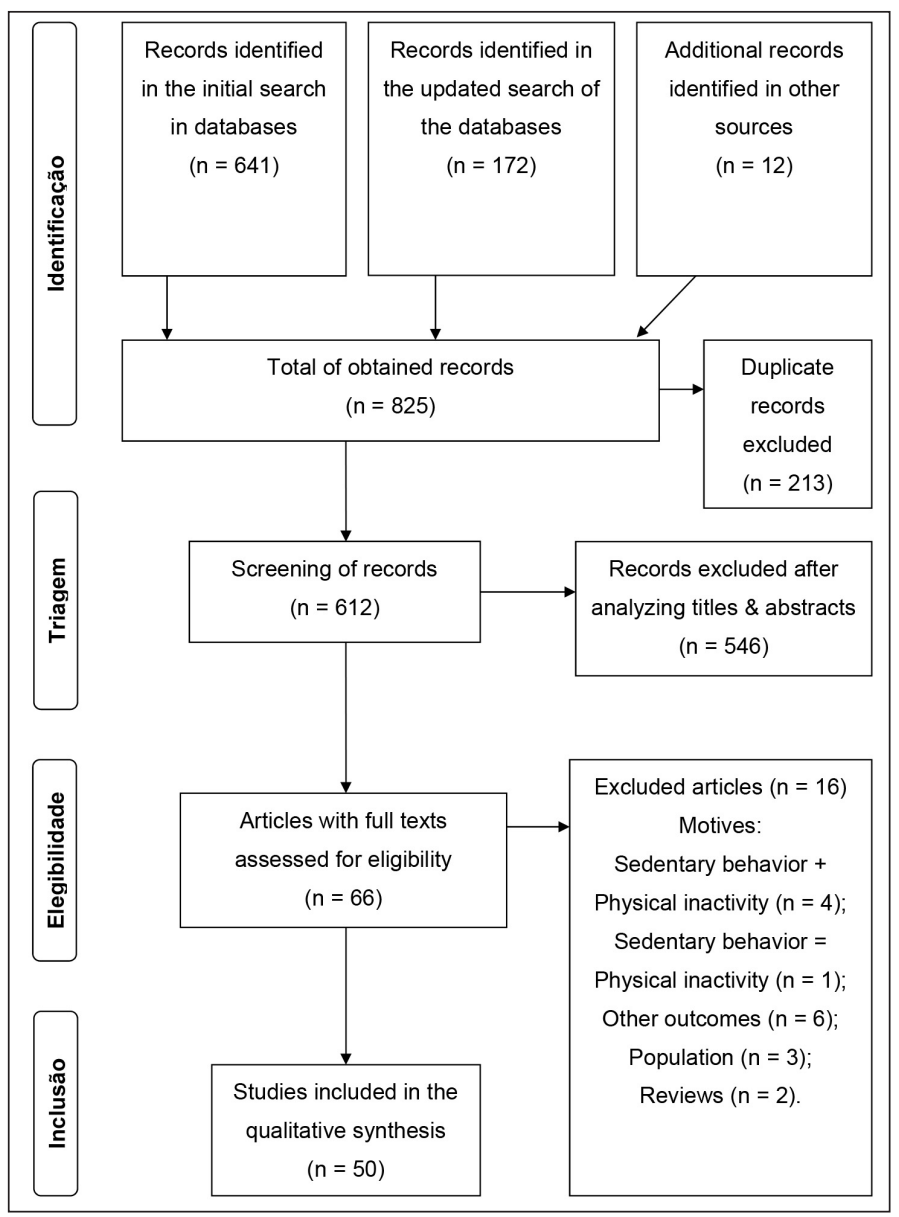

Figure 1. Flowchart of study inclusion.
However, some studies reported a positive association between total sedentary time and adiposity, with children and adolescents in the highest tertile of sedentary time being at a greater risk of being overweight or obese. ${ }^{36,45}$ Total sedentary time was also associated with increased WC.45,53,58 Moreover, a 2-year follow-up of children aged 6 to 8 years showed that total sedentary time was directly associated with increasing $\mathrm{BF}$ percentage..$^{58}$

The evaluation of the patterns of sedentary time accumulation, 80-minute bouts of sedentary time were positively associated with BMI ${ }^{32}$ and WC.32 In addition, short bouts were associated with reduced WC. ${ }^{35}$ Breaks in prolonged sedentary time were also assessed and studies showed that an increased number of breaks was related to reduced $\mathrm{BM}^{35}$ and $\mathrm{WC}^{32,35}$ in children and adolescents.

Regarding the type of sedentary activity, prolonged screen time was frequently associated with increased $\mathrm{BMI}_{1}$, 13,28,38,45,47,52 WC, $28,31,38,45$ waist-to-height ratio (WHR), ${ }^{38}$ and skin-fold thickness. ${ }^{46}$ Moreover, TV time assessed individually was positively associated with BMI, 14,28,33,35,47 $\mathrm{WC}_{1}^{22,26,28,35,39,43,47} \mathrm{WHR}_{1}^{26,48}$ and $\mathrm{BF} .11,14,20,43$ In general, children and adolescents who spent more time watching TV were at a higher risk for being overweight and having high values of BF indicators. Some authors reported that the combined computer and VG usage was positively associated with adiposity. ${ }^{19,28,35}$ However, this association was not demonstrated in most studies when computer orVG usage were assessed individually.21,22,27,29,3,4,47,48

\section{Sedentary Behavior and Lipid Profile}

The data on lipid profile presented in Table 2 show that the majority of studies did not demonstrate an association between total sedentary time and levels of total cholesterol (TC), 18,43,50,56 high-density lipoprotein cholesterol (HDL-C), 18,25,31,35,36,43,50,52,56,58 low-density lipoprotein cholesterol (LDL-C), 18,43,50,52,56,58 very low-density lipoprotein cholesterol (VLDL-C), ${ }^{43}$ non-HDL cholesterol, ${ }^{22,32} \mathrm{TC} / \mathrm{HDL}-\mathrm{C}$ ratio, ${ }^{54,57}$ and triglycerides (TG). $25,31,35,36,40,50,52-54,56-58$ However, some studies indicated that children and adolescents with more sedentary time during the day had higher levels of TG ${ }^{18,43}$ and $\mathrm{LDL}-\mathrm{C}^{53}$ and lower levels of $\mathrm{HDL}-\mathrm{C}^{40,53}$ The analysis focusing on patterns of sedentary time showed that in most studies

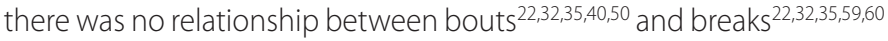
in sedentary time with lipid profile. Only one study showed that children with higher volumes of prolonged bouts of sedentary behavior had reduced levels of $\mathrm{HDL}-\mathrm{C}^{40}$

Reduced levels of HDL-C25,28,31 and high levels of LDL-C 48,52 and TG ${ }^{52}$ have been observed in children and adolescents who reported higher screen time, although most studies indicated a lack of association. In some studies, prolonged TV use was associated with reduced levels of $\mathrm{HDL}^{28}$ and increased levels of LDL. ${ }^{48}$ Moreover, high TV use increased the likelihood of high levels of non-HDL cholesterol in a dose-response relationship.22 An association of VG and computer usage with lipid profile was shown in a few studies, and more time spent using these devices was found to be related to reduced levels of $\mathrm{HDL}{ }^{35,48}$ In contrast, in one study, there was a positive association between the combined use of computers and VGs and HDL levels. ${ }^{39}$ Increasing levels of LDL-C, ${ }_{1}^{47} \mathrm{TG}_{1}{ }^{29}$ and TC/HDL-C ${ }^{24}$ were also detected with increasing VG usage.

\section{Sedentary Behavior and Insulin and Glucose Levels}

There was no relationship between total sedentary time and levels of insulin, ${ }^{35,36,40,43,52,53,56}$ glucose, $25,31,35,36,40,43,50,52,53,56,58$, and insulin resistan$\mathrm{ce}^{36,54,57,58}$ in the analyzed studies (Table 2). Only three studies showed a positive association between total sedentary time and each individual parameter (insulin, ${ }^{58}$ glucose, ${ }_{1}^{18}$ and insulin resistance ${ }^{12}$ ). With regard to the patterns of accumulation of sedentary time, in one randomized study, 
Chart 1. Characteristics of the included studies.

\begin{tabular}{|c|c|c|c|c|c|c|c|c|}
\hline Study & Location & Year & Age (years) & Sample size (F/M) & $\begin{array}{l}\text { Sedentary } \\
\text { behavior }\end{array}$ & $\begin{array}{l}\text { Method of } \\
\text { assessment }\end{array}$ & Factors of cardiovascular risk & AF \\
\hline \multicolumn{9}{|c|}{ Cross-sectional } \\
\hline Ekelund"1 & Europe & 2006 & $\begin{array}{l}9 \text { to } 10 \\
15 \text { to } 16\end{array}$ & $1921(1010 / 911)$ & TV & Questionnaire & $\begin{array}{l}\text { BF, HDL-C, TG, Insulin, Glucose, } \\
\text { SBP, DBP, and CR }\end{array}$ & S \\
\hline Sardinha ${ }^{12}$ & Portugal & 2008 & 9 to 10 & $308(147 / 161)$ & TS & Accelerometry & HOMA-IR & $\mathrm{N}$ \\
\hline Torres $^{13}$ & Spain & 2008 & 3 to 13 & $373(169 / 204)$ & Screen & Questionnaire & $\mathrm{BMI}$ & $\mathrm{N}$ \\
\hline Wells $^{14}$ & Brazil & 2008 & 10 to 12 & $4452(2258 / 2193)$ & TV & \multirow{2}{*}{$\begin{array}{l}\text { Questionnaire } \\
\text { Accelerometry } \\
\text { Questionnaire }\end{array}$} & $\mathrm{BMI}, \mathrm{BF}, \mathrm{SBP}$, and $\mathrm{DBP}$ & $\mathrm{S}$ \\
\hline Martinez-Gomez ${ }^{15}$ & USA & 2009 & 3 to 8 & $111(54 / 57)$ & TS, Screen, TV, CP & & SBP and DBP & N \\
\hline Hardy ${ }^{16}$ & Australia & 2010 & 14 to 17 & $496(206 / 290)$ & Screen & Questionnaire & $\begin{array}{c}\text { HDL-C, LDL-C, TG, Insulin, Glucose, } \\
\text { HOMA-IR, SBP, and DBP }\end{array}$ & N \\
\hline Kang $^{17}$ & Korea & 2010 & 10 to 18 & $845(396 / 449)$ & Screen & Questionnaire & SM & $\mathrm{N}$ \\
\hline Martinez-Gómez ${ }^{18}$ & Spain & 2010 & 13 to 17 & $201(99 / 102)$ & TS & Accelerometry & $\begin{array}{l}\text { BMI, BF, WC, TC, HDL-C, LDL-C, } \\
\text { TG, Glucose, SBP, DBP, and CR }\end{array}$ & N \\
\hline McCrindle ${ }^{19}$ & Canada & 2010 & 14 to 15 & $\begin{array}{c}20719 \\
(10300 / 10419)\end{array}$ & $\mathrm{TV}+\mathrm{VG}, \mathrm{CP}$ & Questionnaire & $\mathrm{BMI}, \mathrm{TC}, \mathrm{SBP}, \mathrm{DBP}$, and CR & N \\
\hline Rivera $^{20}$ & Brazil & 2010 & 7 to 17 & $1253(706 / 547)$ & TV & Questionnaire & $\mathrm{BMI}$ and $\mathrm{BF}$ & $\mathrm{N}$ \\
\hline Alvarez Caro'21 & Spain & 2011 & 6 to 12 & $459(213 / 246)$ & $\mathrm{TS}, \mathrm{TV}+\mathrm{VG}, \mathrm{CP}$ & Questionnaire & $\mathrm{BMI}$ & $\mathrm{N}$ \\
\hline Carson $^{22}$ & EUA & 2011 & 6 to 19 & $2527(1243 / 1284)$ & $\begin{array}{l}\text { TS, Bout, Breaks, } \\
\text { TV, CP }\end{array}$ & $\begin{array}{l}\text { Accelerometry } \\
\text { Questionnaire }\end{array}$ & WC, non-HDL, SBP, and CR & $S$ \\
\hline Danielsen $^{23}$ & Norway & 2011 & 7 to 13 & $86(38 / 48)$ & Screen & Questionnaire & TC, HDL-C, LDL-C, TG, and HOMA-IR & $\mathrm{S}$ \\
\hline Goldfield ${ }^{24}$ & Canada & 2011 & 14 to 18 & $282(196 / 86)$ & Screen, TV, VG, CP & Questionnaire & $\begin{array}{c}\text { WC, HDL-C, LDL-C, TG, CTC/ } \\
\text { HDL-C, SBP, and DBP }\end{array}$ & S \\
\hline $\mathrm{Hsu}^{25}$ & US & 2011 & 13 & $105(79 / 26)$ & TS, Screen & $\begin{array}{l}\text { Accelerometry } \\
\text { Questionnaire }\end{array}$ & WC, HDL-C, TG, Glucose, SBP, DBP, and MS & N \\
\hline Lehto $^{26}$ & Finland & 2011 & 9 to 11 & $604(312 / 292)$ & $\mathrm{TV}, \mathrm{CP}+\mathrm{VG}$ & Questionnaire & WC and WHR & S \\
\hline Altenburg $^{27}$ & Netherlands & 2012 & 12 to 18 & $125(71 / 54)$ & Screen, TV, CP & Questionnaire & $\begin{array}{l}\text { BMI, GC, TC, HDL-C, LDL-C, TG, } \\
\text { Insulin, Glucose, SBP, DBP, and CR }\end{array}$ & S \\
\hline Byun ${ }^{28}$ & Korea & 2012 & 12 to 18 & $577(261 / 316)$ & Screen, TV, CP+VG & Questionnaire & $\mathrm{BMI}, \mathrm{WC}, \mathrm{TC}, \mathrm{HDL}-\mathrm{C}, \mathrm{LDL}-\mathrm{C}, \mathrm{TG}, \mathrm{SBP}$, and DBP & $S$ \\
\hline Martinez-Gomez $z^{29}$ & Spain & 2012 & 13 to 17 & $181(88 / 93)$ & $\mathrm{CP}, \mathrm{VG}$ & Questionnaire & $\begin{array}{l}\text { WC, TC, HDL-C, LDL-C, TG, Insulin, } \\
\text { Glucose, SBP, SBP, MBP, and CR }\end{array}$ & S \\
\hline $\mathrm{Camhi}^{30}$ & US & 2013 & 12 to 18 & $225(118 / 107)$ & Screen, TV, CP & Questionnaire & $\mathrm{CR}$ & $\mathrm{N}$ \\
\hline Chaput $^{31}$ & Canada & 2013 & 8 to 10 & $536(244 / 292)$ & TS, Screen & $\begin{array}{l}\text { Accelerometry } \\
\text { Questionnaire }\end{array}$ & WC, HDL-C, TG, Glucose, SBP, and DBP & S \\
\hline Colley $^{32}$ & Canada & 2013 & 6 to 19 & $1608(799 / 809)$ & TS, Bout, Breaks & Accelerometry & BMI, WC, non-HDL, SBP, and DBP & S \\
\hline Govindan 33 & US & 2013 & 10 to 12 & $1714(906 / 808)$ & $T V, C P, V G$ & Questionnaire & BMI & $\mathrm{N}$ \\
\hline Rey-Lopez ${ }^{34}$ & Europe & 2013 & 12 to 17 & $769(393 / 376)$ & $T V, V G$ & Questionnaire & $\mathrm{CR}$ & $S$ \\
\hline Saunder ${ }^{35}$ & Canada & 2013 & 8 to 11 & $522(236 / 286)$ & $\begin{array}{l}\text { TS, Bout, Breaks, } \\
\text { TV, CP+VG }\end{array}$ & $\begin{array}{l}\text { Accelerometry } \\
\text { Questionnaire }\end{array}$ & BMI, WC, HDL-C, TG, Insulin, Glucose, and CR & S \\
\hline Sisson $^{36}$ & US & 2013 & 12 to 20 & $394(193 / 201)$ & TS & Questionnaire & $\begin{array}{c}\text { BMI, WC, HDL-C, TG, Insulin, Glucose, } \\
\text { HOMA-IR, MBP, CR, and MS }\end{array}$ & $S$ \\
\hline Stamatakis ${ }^{37}$ & Portugal & 2013 & 2 to 12 & $2515(1427 / 1088)$ & $T V, C P, V G$ & Questionnaire & $\mathrm{SBP}, \mathrm{DBP}$, and CR & $\bar{Y}$ \\
\hline Berentzen $^{38}$ & Netherlands & 2014 & 11 to 14 & $1447(744 / 703)$ & Screen, TV, CP & Questionnaire & $\mathrm{BMI}, \mathrm{WC}, \mathrm{WHR}, \mathrm{TC} / \mathrm{HDL}-\mathrm{C}, \mathrm{SBP}$, and DBP & $\mathrm{N}$ \\
\hline Chinapaw $^{39}$ & Netherlands & 2014 & 5 to 6 & $1961(961 / 1000)$ & $\mathrm{TV}, \mathrm{CP}+\mathrm{VG}$ & Questionnaire & WC, HDL-C, LDL-C, TG, Glucose, MBP, and CR & $\mathrm{Y}$ \\
\hline Clifffo & Australia & 2014 & 5 to 9 & $120(74 / 46)$ & TS, Bout & Accelerometry & $\mathrm{HDL}, \mathrm{TG}$, Insulin, Glucose, SBP, DBP, CR & Y \\
\hline Crispim $^{41}$ & Brazil & 2014 & 2 to 5 & $276(131 / 145)$ & TV & Questionnaire & SBP and DBP & $\mathrm{N}$ \\
\hline Flynn ${ }^{42}$ & EUA & 2014 & 10 to 12 & $1104(565 / 539)$ & Screen & Questionnaire & HDL-C & $\mathrm{N}$ \\
\hline Väistö43 & Finland & 2014 & 6 to 8 & $468(225 / 243)$ & TS, Screen, TV & Questionnaire & $\begin{array}{l}\mathrm{BF}, \mathrm{WC}, \mathrm{TC}, \mathrm{HDL}-\mathrm{C}, \mathrm{LDL}-\mathrm{C}, \mathrm{VLDL}-\mathrm{C}, \mathrm{TG} \text {, } \\
\text { Insulin, Glucose, SBP, DBP, and CR }\end{array}$ & Y \\
\hline do Prado Junior ${ }^{44}$ & Brazil & 2015 & 10 to 19 & $676(378 / 298)$ & Screen & Questionnaire & $\mathrm{TC}, \mathrm{LDL}-\mathrm{C}, \mathrm{HDL}-\mathrm{C}, \mathrm{TG}, \mathrm{SBP}$, and DBP & $\mathrm{N}$ \\
\hline Herman ${ }^{45}$ & Canada & 2015 & 8 to 10 & $534(248 / 286)$ & TS, Screen, TV & $\begin{array}{l}\text { Accelerometry } \\
\text { Ouestionnaire }\end{array}$ & $B M I$ and $W C$ & N \\
\hline Rendo-Urteaga ${ }^{46}$ & Europe & 2015 & 12 to 17 & $769(404 / 365)$ & Screen & Questionnaire & $\mathrm{BF}, \mathrm{TC} / \mathrm{HDL}-\mathrm{C}, \mathrm{TG}, \mathrm{HOMA}-\mathrm{IR}, \mathrm{SBP}$, and CR & $\mathrm{N}$ \\
\hline Robinson ${ }^{47}$ & Australia & 2015 & 7 to 10 & 264 & $T V, C P, V G$, Screen & Questionnaire & $\begin{array}{l}\text { BMI, WC, TC, HDL-C, LDL-C, } \\
\text { TG, SBP, DBP, and CR }\end{array}$ & Y \\
\hline Safirit8 & Iran & 2015 & 10 to 18 & $5625(2801 / 2824)$ & TV, CP, Scree & Questionnaire & $\begin{array}{l}\text { BMI, WHR, TC, HDL-C, LDL-C, TG, } \\
\text { Glucose, SBP, DBP, and MS }\end{array}$ & N \\
\hline Vaccaro 49 & US & 2016 & 6 to 12 & 614 & Screen & Questionnaire & BMI & $\mathrm{N}$ \\
\hline Batalau ${ }^{50}$ & Portugal & 2017 & 7 to 10 & $77(31 / 46)$ & TS, Bout, Screen & $\begin{array}{l}\text { Accelerometry } \\
\text { Questionnaire }\end{array}$ & TC,HDL-C, LDL-C, TG, Glucose,SBP, and DBP & N \\
\hline Katzmarzyk $^{51}$ & US & 2017 & 5 to 18 & 357 & TV & Questionnaire & $\begin{array}{l}\text { BMI, BF, WC, HDL-C, TG, } \\
\text { Glucose, SBP, DBP, and CR }\end{array}$ & Y \\
\hline Norman $^{52}$ & US & 2017 & 11 to 13 & $106(54 / 52)$ & TS, Screen & $\begin{array}{c}\text { Accelerometry } \\
\text { Questionnaire }\end{array}$ & $\begin{array}{l}\text { BMI, GC, WC, HDL-C, LDL-C, TG, } \\
\text { Insulin, Glucose, SBP, and DBP }\end{array}$ & Y \\
\hline Hansen $^{53}$ & $\mathrm{ICAD}^{*}$ & 2018 & 4 to 18 & $18200(9207 / 8993)$ & TS & Accelerometry & WC, HDL-C, LDL-C, TG, Insulin, Glucose, SBP & $\mathrm{N}$ \\
\hline Cristi-Montero $^{54}$ & Europe & 2019 & 12 to 17 & $548(289 / 259)$ & TS & Accelerometry & $\mathrm{BF}, \mathrm{TC} / \mathrm{HDL}-\mathrm{C}, \mathrm{TG}, \mathrm{HOMA}-\mathrm{R}, \mathrm{SBP}$, and CR & Y \\
\hline & & & & & gitudinal & & & \\
\hline de Moraes $^{55}$ & Europe & 2015 & 2 to 9 & $5061(2576 / 2485)$ & Screen & Questionnaire & SBP and DBP & $\mathrm{N}$ \\
\hline Stamatakis $^{56}$ & England & 2015 & 11 to 12 & $4639(2459 / 2180)$ & TS & Accelerometry & $\begin{array}{l}\text { BMI, BF, WC, TC, HDL-C, LDL-C, TG, } \\
\text { Insulin, Glucose, SBP, DBP, and CR }\end{array}$ & Y \\
\hline Norman ${ }^{52}$ & US & 2017 & 11 to 13 & $106(54 / 52)$ & TS, Screen & $\begin{array}{l}\text { Accelerometry } \\
\text { Questionnaire }\end{array}$ & $\begin{array}{l}\text { IMC, GC, PC, HDL, LDL, TG, } \\
\text { Insulin, Glucose, PAS e PAD }\end{array}$ & Y \\
\hline Skrede $^{57}$ & Norway & 2017 & 10 & $700(356 / 344)$ & $\mathrm{S}$ & Accelerometry & WC, TC/HDL-C, TG, HOMA-IR, SBP, and CR & $\mathrm{N}$ \\
\hline Väistö58 & Finland & 2019 & 6 to 8 & $258(140 / 118)$ & TS & Accelerometry & $\begin{array}{c}\text { BF, WC, HDL-C, LDL-C, TG, Insulin, } \\
\text { Glucose, HOMA-IR, SBP, DBP, and CR }\end{array}$ & N \\
\hline & & & & & domized & & & \\
\hline Saunders ${ }^{59}$ & Canada & 2013 & 10 to 14 & $19(8 / 11)$ & Breaks & Observation & HDL-C, LDL-C, TG, Insulin, and Glucose & $\mathrm{Y}$ \\
\hline Belcher $^{60}$ & USA & 2015 & 7 to 11 & $28(15 / 13)$ & Breaks & Observation & $\mathrm{TG}$, Insulin, and Glucose & $\mathrm{N}$ \\
\hline
\end{tabular}

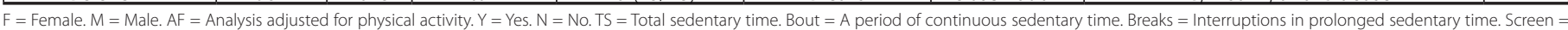

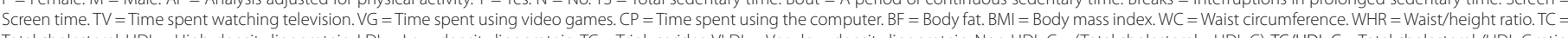

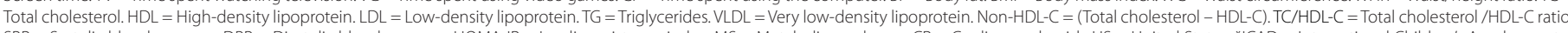

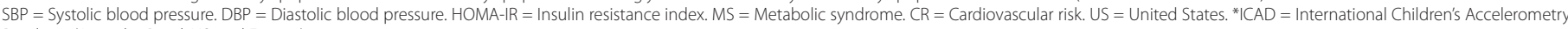
Database (Australia, Brazil, US, and Europe). 
Table 1. Sedentary behavior and body adiposity

\begin{tabular}{|c|c|c|c|c|}
\hline $\begin{array}{c}\text { Sedentary } \\
\text { behavior }\end{array}$ & Adiposity & $\begin{array}{c}\text { Positive } \\
\text { association }\end{array}$ & $\begin{array}{c}\text { Negative } \\
\text { association }\end{array}$ & $\begin{array}{l}\text { Lack of } \\
\text { association }\end{array}$ \\
\hline \multirow[t]{4}{*}{ TS } & BMI & 36,45 & & $\begin{array}{c}18,21,32,35,52 \\
52 \mathrm{~L}, 56\end{array}$ \\
\hline & $\mathrm{BF} \%$ (DEXA) & 58 & & $43,52,52 \mathrm{~L}, 56$ \\
\hline & Skin folds & & & 18,54 \\
\hline & WC & $45,53,58$ & & $\begin{array}{c}18,22,25,31,32,35,3 \\
6,43,52,52 L, 56,57\end{array}$ \\
\hline \multirow[t]{2}{*}{ Bout of ST } & BMI & 32,35 & & \\
\hline & WC & 32,35 & & 22 \\
\hline \multirow[t]{2}{*}{ Breaks in ST } & BMI & & 35 & 32 \\
\hline & WC & & 32,35 & 22 \\
\hline \multirow[t]{5}{*}{ Screen } & BMI & $\begin{array}{c}13,28,38,45,47 \\
49,52,52 \mathrm{~L}\end{array}$ & & 27,48 \\
\hline & $\mathrm{BF} \%$ (DEXA) & & & $27,43,52,52 \mathrm{~L}$ \\
\hline & Skin folds & 46 & & \\
\hline & WC & $28,31,38,45$ & & $25,43,47,52,52 \mathrm{~L}$ \\
\hline & RCE & 38 & & 48 \\
\hline \multirow[t]{5}{*}{ Television } & BMI & $14,28,33,35,47$ & & $20,27,45,48,51$ \\
\hline & BF\% (DEXA) & 43,51 & & 27 \\
\hline & Skin folds & $11,14,20$ & & \\
\hline & WC & $\begin{array}{c}22,26,28,35,39 \\
43,47,51\end{array}$ & & 45 \\
\hline & RCE & 26,48 & & \\
\hline \multirow[t]{4}{*}{ Computer } & $\mathrm{BMI}$ & 19 & & $21,27,33,47,48$ \\
\hline & $\mathrm{BF} \%$ (DEXA) & & & 27 \\
\hline & WC & & & $22,29,47$ \\
\hline & RCE & & & 48 \\
\hline \multirow[t]{2}{*}{ Vídeo Game } & $\mathrm{BMI}$ & & & 33,47 \\
\hline & WC & & & 29,47 \\
\hline
\end{tabular}

$\mathrm{ST}=$ Sedentary time; $\mathrm{BMI}=$ Body mass index; \%GC (DEXA) = Total body fat percentage determined by bone densitometry; WC = Waist circumference; WHR $=$ Waist/height ratio. ${ }^{52 \mathrm{~L}}=$ Reference 52 with the longitudinal analysis

the levels of insulin and glucose were reduced after a period of sedentary time with breaks compared with the same period without breaks. ${ }^{60}$

The analysis of the type of sedentary behavior showed that adolescents with a screen time of 2 or more hours per day were at a higher risk of abnormal levels of insulin. ${ }^{16}$ In addition, greater exposure to screen time was associated with elevated insulin resistance. ${ }^{16,23}$ However, the majority of studies did not indicate an association between screen time and levels of insulin, glucose, and insulin resistance. $25,27,31,43,46,48,50,52$

\section{Sedentary Behavior and Blood Pressure}

The observed relationships between sedentary behavior and BP are shown in Table 3. Only two studies demonstrated an association between total sedentary time and systolic blood pressure (SBP), in which adolescents with longer total sedentary time had higher levels of $\mathrm{SBP}_{1}^{18,53}$ a finding that contrasts most studies reporting a lack of association. ${ }^{15,22,31,32,40,43,50,52,54,56-58}$ Prolonged bouts of sedentary time $22,32,40,50$ and breaks ${ }^{32}$ were not associated with BP. However, there were associations with specific indicators of sedentary behavior. Children and adolescents with prolonged screen exposure had higher values of BP. 15,25,52,55 After a 2-year follow-up, children with screen time of 2 or more hours per
Table 2. Sedentary behavior associated with lipid profile, insulin, and glucose.

\begin{tabular}{|c|c|c|c|c|}
\hline $\begin{array}{c}\text { Sedentary } \\
\text { behavior }\end{array}$ & $\begin{array}{l}\text { Biochemical } \\
\text { parameters }\end{array}$ & \begin{tabular}{|c|} 
Positive \\
association \\
\end{tabular} & \begin{tabular}{|c|} 
Negative \\
association \\
\end{tabular} & $\begin{array}{c}\text { Lack of } \\
\text { association }\end{array}$ \\
\hline \multirow[t]{10}{*}{ ST } & Total cholesterol & & & $18,43,50,56$ \\
\hline & $\mathrm{HDL}-\mathrm{C}$ & & 40,53 & $\begin{array}{c}18,25,31,35,36,43 \\
, 50,52,52 \mathrm{~L}, 56,58\end{array}$ \\
\hline & LDL-C & 53 & & $18,43,50,52,52 \mathrm{~L}, 56,58$ \\
\hline & Non-HDL-C & & & 22,32 \\
\hline & $\mathrm{TC} / \mathrm{HDL}-\mathrm{C}$ & & & 54,57 \\
\hline & VLDL-C & & & 43 \\
\hline & Triglycerides & 18,43 & & $\begin{array}{c}25,31,35,36,40,50,52- \\
54,56-58 \\
\end{array}$ \\
\hline & Insulin & 58 & & $\begin{array}{c}35,36,40,43,52,52 \mathrm{~L} \\
53,56 \\
\end{array}$ \\
\hline & Glucose & 18 & & $\begin{array}{c}25,31,35,36,40,43,5 \\
0,52,52 \mathrm{~L}, 53,56,58 \\
\end{array}$ \\
\hline & HOMA-IR & 12 & & $36,54,57,58$ \\
\hline \multirow[t]{7}{*}{ Bout of ST } & Total cholesterol & & & 50 \\
\hline & $\mathrm{HDL}-\mathrm{C}$ & & 40 & 35,50 \\
\hline & LDL-C & & & 50 \\
\hline & Non-HDL-C & & & 22,32 \\
\hline & Triglycerides & & & $35,40,50$ \\
\hline & Insulin & & & 35,40 \\
\hline & Glucose & & & $35,40,50$ \\
\hline \multirow[t]{6}{*}{ Breaks in ST } & $\mathrm{HDL}-\mathrm{C}$ & & & 35,59 \\
\hline & LDL-C & & & 59 \\
\hline & Non-HDL-C & & & 22,32 \\
\hline & Triglycerides & & & $35,59,60$ \\
\hline & Insulin & & 60 & 35,59 \\
\hline & Glucose & & 60 & 35,59 \\
\hline \multirow[t]{9}{*}{ Screen } & |Total cholesterol| & & & $\begin{array}{c}23,24,27,28,43,44,47 \\
48,50 \\
\end{array}$ \\
\hline & $\mathrm{HDL}-\mathrm{C}$ & & $25,28,31$ & $\begin{array}{c}16,23,24,27,42- \\
44,47,48,50,52,52 \mathrm{~L} \\
\end{array}$ \\
\hline & LDL-C & $48,52 \mathrm{~L}$ & & $\begin{array}{c}16,23,24,27,28,43,44 \\
47,50,52\end{array}$ \\
\hline & $\mathrm{TC} / \mathrm{HDL}-\mathrm{C}$ & & & $24,38,46$ \\
\hline & VLDL-C & & & 43 \\
\hline & Triglycerides & $52 \mathrm{~L}$ & & $\begin{array}{c}16,23- \\
25,27,28,31,43,44,46- \\
48,50,52 \\
\end{array}$ \\
\hline & Insulin & 16 & & $27,43,52,52 \mathrm{~L}$ \\
\hline & Glucose & & & $\begin{array}{c}16,25,27,31,43,48,50 \\
52,52 \mathrm{~L} \\
\end{array}$ \\
\hline & HOMA-IR & 16,23 & & 46 \\
\hline \multirow[t]{9}{*}{ Television } & Total cholesterol & & & $24,27,28,43,47,48$ \\
\hline & $\mathrm{HDL}-\mathrm{C}$ & & 28 & \begin{tabular}{|c}
$11,24,27,35,39,43,47$ \\
48,51 \\
\end{tabular} \\
\hline & LDL-C & 48 & & $24,27,28,39,43,47$ \\
\hline & Non-HDL-C & 22 & & \\
\hline & $\mathrm{TC} / \mathrm{HDL}-\mathrm{C}$ & & & 24,38 \\
\hline & VLDL-C & & & 43 \\
\hline & Triglycerides & 51 & & $\begin{array}{c}11,24,27,28,35,39,43 \\
47,48 \\
\end{array}$ \\
\hline & Insulin & & & $11,27,35,43$ \\
\hline & Glucose & 51 & & $11,27,35,39,43,48$ \\
\hline \multirow[t]{8}{*}{ Computer } & Total cholesterol & & 27 & $19,24,29,47,48$ \\
\hline & $\mathrm{HDL}-\mathrm{C}$ & & 48 & $24,27,29,47$ \\
\hline & LDL-C & & 27 & $24,29,47,48$ \\
\hline & Non-HDL-C & & & 22 \\
\hline & $\mathrm{TC} / \mathrm{HDL}-\mathrm{C}$ & & & 24,38 \\
\hline & Triglycerides & & & $24,27,29,47,48$ \\
\hline & Insulin & & & 27,29 \\
\hline & Glucose & & & $27,29,48$ \\
\hline \multirow[t]{7}{*}{ Vídeo Game } & Total cholesterol & & & $24,29,47$ \\
\hline & $\mathrm{HDL}-\mathrm{C}$ & & & $24,29,47$ \\
\hline & LDL-C & 47 & & 24,29 \\
\hline & $\mathrm{TC} / \mathrm{HDL}-\mathrm{C}$ & 24 & & \\
\hline & Triglycerides & 29 & & 24,47 \\
\hline & Insulin & & & 29 \\
\hline & 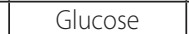 & & & 29 \\
\hline
\end{tabular}

ST = Sedentary time $\cdot \mathrm{HDL}=$ High-densitylipoproteins: $\mathrm{LDL}=$ low-density lipoproteins; Non-HDL-C=Total choles terol- HDL-C;TC/HDL-C = Total cholesterol /HDL-C ratio; VLDL = very low-density lipoproteins; HOMA-IR = Insulin resistance index. $52 \mathrm{~L}=$ Reference 52 with the longitudinal analysis. 
Table 3. Sedentary behavior associated with blood pressure and cardiovascular risk.

\begin{tabular}{|c|c|c|c|c|}
\hline $\begin{array}{l}\text { Sedentary } \\
\text { behavior }\end{array}$ & $\begin{array}{c}\text { BP and } \\
\text { CR }\end{array}$ & $\begin{array}{c}\text { Positive } \\
\text { association }\end{array}$ & $\begin{array}{r}\text { Negative } \\
\text { associatio }\end{array}$ & $\begin{array}{c}\text { Lack of } \\
\text { association }\end{array}$ \\
\hline \multirow[t]{5}{*}{ ST } & SBP & 18,53 & & $\begin{array}{c}15,22,25,31,32,40,43,50,52,52 L \\
54,56-58\end{array}$ \\
\hline & DBP & & & $\begin{array}{c}15,18,25,31,32,40,43 \\
, 50,52,52 L, 56,58\end{array}$ \\
\hline & MBP & & & 36 \\
\hline & $C R$ & $18,54,58$ & & $22,35,36,40,43,56,57$ \\
\hline & MS & & & 25,36 \\
\hline \multirow[t]{3}{*}{ Bout of TS } & SBP & & & $22,32,40,50$ \\
\hline & DBP & & & $32,40,50$ \\
\hline & $C R$ & & 35 & 22,40 \\
\hline \multirow[t]{3}{*}{ Breaks in ST } & SBP & & & 22,32 \\
\hline & DBP & & & 32 \\
\hline & $C R$ & & 35 & 22 \\
\hline \multirow[t]{4}{*}{ Screen } & SBP & $15,25,55$ & & $\begin{array}{c}16,24,27,28,31,38,43,44,46 \\
48,50,52,52 \mathrm{~L}\end{array}$ \\
\hline & DBP & 52,55 & & $\begin{array}{c}15,16,24,25,27,28,31,38 \\
, 43,44,47,48,50,52 \mathrm{~L}\end{array}$ \\
\hline & $C R$ & 43 & & $27,30,46,47$ \\
\hline & MS & 17,25 & & 48 \\
\hline \multirow[t]{5}{*}{ Television } & SBP & $14,15,37,43,47,48$ & & $11,22,24,27,28,38,41,51$ \\
\hline & DBP & $14,15,37,48$ & & $11,24,27,28,38,41,43,47,51$ \\
\hline & MBP & & & 39 \\
\hline & $C R$ & $22,35,37,43,51$ & & $11,27,30,34,39,47$ \\
\hline & MS & & & 48 \\
\hline \multirow[t]{5}{*}{ Computer } & SBP & & & $15,19,22,24,27,29,37,38,47,48$ \\
\hline & DBP & & & $15,19,24,27,29,37,38,47,48$ \\
\hline & MBP & & & 29 \\
\hline & $C R$ & & & $19,22,27,29,30,37,47$ \\
\hline & MS & & & 48 \\
\hline \multirow[t]{4}{*}{ Vídeo Game } & SBP & 24 & & $29,37,47$ \\
\hline & DBP & 29 & & $24,37,47$ \\
\hline & MBP & 29 & & \\
\hline & $C R$ & 29,34 & & 37,47 \\
\hline
\end{tabular}

$\mathrm{ST}=$ Sedentary time $\cdot \mathrm{BP}=$ Blood pressure $\cdot \mathrm{SBP}=$ Systolic blood pressure $\mathrm{DBP}=$ Diastolic blood pressure $\cdot \mathrm{MBP}=$ Mean blood pressure; $C R=$ Cardiovascular risk; $M S=$ Metabolic syndrome. $52 \mathrm{~L}=$ Reference 52 with the longitudinal analysis.

day had a higher incidence of elevated $B \mathrm{P}^{55}$ Among screen behaviors, TV time was positively associated with $B P_{1}^{14,15,37,43,47,48}$ which indicates that the increase in time spent watching TV is related to increased SBP14,15,37,43,47,48 and DPB 14,15,37,48 in children and adolescents. Moreover, $T V$ viewing for more than 2 hours per day was related to increased BP compared with TV time limited to one hour per day. ${ }^{37}$ Two other studies also reported that VG usage was positively associated with elevated BP in adolescents. 24,29

\section{Sedentary Behavior and Combination of Risk Factors}

As presented in Table 3, three studies showed higher CR among adolescents with longer sedentary time. ${ }^{18,54,58}$ One study on the patterns of sedentary time accumulation showed that a frequent breaks and short sedentary bouts was associated with reduced CR among children and adolescents. ${ }^{35}$ Some authors reported that increased screen time was associated with increased $C R^{43}$ and prevalence of metabolic syndrome. ${ }^{17,25} \mathrm{~A}$ longer exposure to TV was associated with higher CR. 22,35,37,43 Prolonged VG use ${ }^{29,34}$ was also associated with increased CR. Moreover, higher CR was observed in children and adolescents who spent more time on combined screen activities (computer+VG ${ }^{35}$ and $T V+V G^{19}$ ).

\section{DISCUSSION}

The present study demonstrated that sedentary behavior is associated with risk factors for cardiovascular disease in children and adolescents. Moreover, the frequency of this association appeared to depend on the assessed behavior indicator and the analyzed risk factor. These observations have been confirmed by the growing number of studies on the subject in recent years. This reflects the recognition that sedentariness as a health behavior is an important and necessary area of study. ${ }^{2}$ Although there are numerous studies with adults, those involving the pediatric population are still scarce. ${ }^{4}$

In addition to total sedentary time, screen time and TV time were the most used indicators to determine sedentary behavior. Although the use of electronic media is a popular and frequent sedentary activity, the overlap of these daily activities is a reality that makes sedentary behavior a complex issue, which indicates that it cannot be limited to a single component. ${ }^{1}$

It is important to consider that TV time and computer time, among other screen activities, are indicators and determinants of sedentary behavior that have been studied using subjective methods. On the other hand, the assessment of total sedentary time provides a global measure of this behavior. This measurement can be performed using objective and subjective methods such as accelerometry and activity diaries, respectively. These are distinct indicators of sedentary behavior, both of which have limitations. ${ }^{61}$ Using subjective measures incorporates the risk of biases related to response, memory, and social desirability, which are characteristic of assessment questionnaires. ${ }^{62}$ Accelerometry, an objective measure, does not provide information about context and type of activities, ${ }_{1}^{61}$ and the use of different methods (including definitions of usage days and usage time) may hinder the comparison of results. ${ }^{63}$ In this sense, the measures provide important information on sedentary behavior and the use of both approaches, whenever possible, has been recommended. ${ }^{61}$

Several studies have demonstrated the association between sedentary activities and CR factors in children and adolescents using different indicators, which points to the deleterious impact of sedentary behavior on health. Lipase lipoprotein activity suppression may occur as a result of sustained inactivity of the major muscle groups of legs and trunk inherent to sedentary activities, ${ }^{64}$ in addition to changes in the response of myosin in skeletal muscle that promote endothelial dysfunction of the cardiovascular system through the increase in pro-inflammatory adipokines. ${ }^{65}$ Consequently, these changes may occur in the early stages of the pathological process of atherosclerosis, leading to the gradual development of cardiovascular diseases. ${ }^{65}$

The qualitative analysis of the studies showed that sedentary behavior, indicated primarily by prolonged exposure to screen time, was frequently associated with higher adiposity indices, $_{1}^{13,28,31,38,45-47,49,52}$ elevated BP, 15,25,52,55 low values of HDL cholesterol, $^{25,28,31}$ elevated levels of serum insulin ${ }^{16}$ and insulin resistance, ${ }^{16,23}$ increased risk of metabolic syndrome $e^{1,7,25}$ and higher CR. ${ }^{43}$ When TV time was analyzed individually as an indicator of sedentary behavior, the results showed that prolonged time spent watching TV was associated with increased body adiposity, ${ }^{11,14,20,22,26,28,33,35,39,43,47,48,51}$ elevated SBP 14,15,37,43,47,48 and DBP, 14,15,37,38 reduced levels of HDL-C, ${ }^{28}$ and increased $C R \cdot 22,35,37,43,51$ These results indicate the importance of promoting the reduction in sedentary behavior by reducing the 
exposure of children and adolescents to screen and TV time. This strategy is essential because of the high and increasing prevalence of sedentary activities among this population. ${ }^{7}$ Moreover, it is important to consider that individuals tend to increase their total energy intake (including unhealthy foods) during TV viewing, which affects the energy balance and increases health risks. ${ }^{66}$

Considering that sedentary behavior and physical inactivity are distinct terms and behaviors, their quantification and related recommendations should also be specific. ${ }^{3}$ Guidelines on sedentary behavior intended for the pediatric population recommend the limitation of screen time, especially TV time, to 2 hours per day. ${ }^{67}$ The studies analyzing screen time of children and adolescents reported that exceeding the recommended time was associated with increased adiposity, ${ }_{1}^{38}$ elevated $\mathrm{BP}_{1}^{37,55}$ increased insulin levels, ${ }^{16}$ increased HOMA-IR, ${ }^{16}$ and elevated $C R{ }^{37}$ After a 2-year follow-up of children aged 2 to 9 years, the incidence of elevated BP was higher in those with a screen time of 2 or more hours per day than in those who reduced it to less than 2 hours per day. ${ }^{55}$ It should be noted that despite the obtained results, the recommendation to limitTV time to 2 hours per day is based on a single and exclusive determinant. This means that a limit of 2 hours does not account for the complexity and potential interactions between the multiple determinants of sedentary behavior, such as combined TV and VG time or combined TV and computer time. Moreover, more recent studies suggest that the limitation of screen time to 1 to 1.5 hours daily may be more effective in avoiding obesity. ${ }^{68}$

Although the current recommendations also include the reduction in time spent in sedentary transportation and prolonged sitting time, ${ }^{5}$ cut-off points have not yet been established for the limitation of total sedentary time. Several authors have assessed the total sedentary time per day and reported mean values varying from 241 to 549 minutes per day. Although with a lower level of evidence in the studies, the results indicated that children and adolescents with higher sedentary time were more likely to be overweight or obese ${ }^{36,45}$ and had higher SBP, 18,53 insulin, ${ }^{58}$ glucose, ${ }^{18}$ insulin resistance, ${ }^{12}$ triglycerides, $^{18,43}{ }^{\text {LDL-C, }}{ }^{53}$ and $\mathrm{CR}^{18,54,58}$ and reduced levels of HDL-C.40,53 This suggests that the deleterious effect of prolonged total sedentary time on health stems from childhood. In a 2-year follow-up study, a reduction in total sedentary time was associated with a reduction in BF, WC, levels of insulin, and cardiometabolic risk among children. ${ }^{58}$

Regarding the impact that sedentary behavior may have on health, in addition to total sedentary time and other related activities, the patterns of sedentary time accumulation were also investigated. 22,32,35,40,50,59,60 Some authors analyzed bouts of sedentary time over a continuous period of sedentary time, as well as breaks in prolonged sedentary time. Prolonged bouts of sedentary time have been associated with overweight ${ }^{32}$ and lower levels of HDL-C.. ${ }^{40}$ On the contrary, short bouts of sedentary time mitigated CV. ${ }^{35}$ Moreover, a higher frequency of breaks in sedentary time was associated with low $\mathrm{BMI}_{1}^{35}$ reduction in insulin and glucose levels, ${ }^{60}$ and low CR. ${ }^{35}$

Short bouts of sedentary behavior and breaks in sedentary behavior may be related to $C R$ reduction, which suggests that children and adolescents who frequently interrupt sedentary time are at a lower risk than those who spend long periods of time sitting. ${ }^{32,35,40,60}$ In a randomized study, lower levels of insulin and blood glucose were detected when 3-minute breaks in sitting time were taken every 30 minutes during a 3-hour sedentary bout, ${ }^{60}$ which indicated an effect on glucose homeostasis and lower endogenous insulin production. These results suggest that the acute metabolic effect of sedentary time interruption is a potential strategy for the prevention of $C R$, although the long-term consequences of the accumulation patterns of sedentary time have not been determined.

In some studies, sedentary behavior was analyzed separately, i.e., on weekdays and weekends. ${ }^{16,17,26,31,32,34}$ Some authors reported a positive association between prolonged TV and VG time on weekends with the assessed risk factors. ${ }^{17,34}$ Considering that the amount of sedentary activities of children and adolescents may be higher in certain periods of the day and the week ${ }^{69}$ and may be associated with other determinants, ${ }^{70}$ data on the latter are relevant for understanding and proposing interventions related to sedentary behavior reduction.

According to the findings of the present review, total sedentary time, type of activity, and pattern of sedentary time accumulation appear to be associated with cardiovascular health. However, the study had the following limitations: because of the heterogeneity of the analyzed studies regarding participants and measures of outcomes, a qualitative synthesis describing the studies and their findings was conducted rather than a meta-analysis. In addition, the fact that the majority were cros$\mathrm{s}$-sectional studies hindered the establishment of a causal relationship between sedentary behavior and CR.

Additionally important is the fact that, in general, the studies showed an association between a single indicator of sedentary behavior and the analyzed CR factors, which indicates the limitations of the findings. Considering the multiple components, complexity, and potential interactions between the multiple determinants of sedentary behavior, it is necessary to use methods that allow for the evaluation of sedentary behavior as a construct. Alternative methods have recently been used to evaluate the lifestyle of adolescents, ${ }^{71}$ in which the approach with a latent variable allows concomitant analysis through the iteration of manifesting variables.

\section{CONCLUSION}

Although not all studies support this relationship, a growing body of evidence indicates that sedentary behavior is associated with adverse effects on health and is a risk factor for the development of cardiovascular disease in children and adolescents. Prolonged sedentary time, especially prolonged exposure to screen and TV time, is associated with CR factors. In addition, prolonged sedentary bouts and infrequent breaks in sedentary time appear to compromise the cardiometabolic profile. Therefore, it is important to individually consider the distinct indicators and patterns of this behavior and their influence on health.

Currently, understanding the complex relationships between sedentary behavior determinants and the health of the pediatric population is an extremely important need, especially because this childhood behavior tends to persist into adulthood, more so than physical activity habits. Thus, new studies should be conducted for the development of proposals for interventions that enable the mitigation of the adverse effects of sedentary behavior on health and a better understanding of the multiple and overlapping aspects of this behavior and its influence on health. The aim is to promote the creation of guidelines for this population.

All authors declare no potential conflict of interest related to this article

AUTHORS' CONTRIBUTIONS: Each author made significant individual contributions to this manuscript. KLRC (0000-0002-9117-6129)*: conception of the work, acquisition, analysis and interpretation of data, writing; PRSA (0000-0002-4327-9190)* analysis and interpretation of data for the work, critical review of its intellectual content; VPNM (00000002-2037-0573)*: analysis and interpretation of data for the work, writing; SEP (0000-0003-0656-1485)*: interpretation of data for the work, critical review of its intellectual content; SCCF (0000-0001-7934-4858)*: conception of the work, critical review of its intellectual content. All authors approved the final version of the manuscript. *ORCID (Open Researcher and Contributor ID). 


\section{REFERÊNCIAS}

1. Pate RR, O'Neill JR, Lobelo F. The evolving definition of "sedentary". Exerc Sport Sci Rev. 2008;36(4):173-8.

2. Spanier PA, Marshall SJ, Faulkner GE. Tackling the obesity pandemic: a call for sedentary behaviour research. Can J Public Health. 2006;97(3):255-7.

3. Hamilton MT, Healy GN, Dunstan DW, Zderic TW, Owen N. Too Little Exercise and Too Much Sitting: Inactivity Physiology and the Need for New Recommendations on Sedentary Behavior. Curr Cardiovasc Risk Rep. 2008;2(4):292-8.

4. Ford ES, Caspersen CJ. Sedentary behaviour and cardiovascular disease: a review of prospective studies. Int J Epidemiol. 2012;41(5):1338-53

5. Tremblay MS, Leblanc AG, Janssen I, Kho ME, Hicks A, Murumets K, et al. Canadian sedentary behaviour guidelines for children and youth. Appl Physiol Nutr Metab. 2011;36(1):59-64.

6. Healy GN, Dunstan DW, Salmon J, Cerin E, Shaw JE, Zimmet PZ, et al. Breaks in sedentary time: beneficial associations with metabolic risk. Diabetes Care. 2008;31(4):661-6.

7. Tremblay MS, LeBlanc AG, Kho ME, Saunders TJ, Larouche R, Colley RC, et al. Systematic review of sedentary behaviour and health indicators in school-aged children and youth. Int J Behav Nutr Phys Act. 2011;8:98.

8. Saunders TJ, Chaput JP, Tremblay MS. Sedentary behaviour as an emerging risk factor for cardiometabolic diseases in children and youth. Can J Diabetes. 2014;38(1):53-61.

9. Liberati A, Altman DG, Tetzlaff J, Mulrow C, Gotzsche PC, loannidis JP, et al. The PRISMA statement for reporting systematic reviews and meta-analyses of studies that evaluate health care interventions: explanation and elaboration. PLoS Med. 2009;6(7):e1000100.

10. Downs SH, Black N. The feasibility of creating a checklist for the assessment of the methodological quality both of randomised and non-randomised studies of health care interventions. J Epidemiol Community Health. 1998;52(6):377-84

11. Ekelund U, Brage S, Froberg K, Harro M, Anderssen SA, Sardinha LB, et al. TV viewing and physical activity are independently associated with metabolic risk in children: the European Youth Heart Study. PLoS Med. 2006;3(12):e488.

12. Sardinha LB, Andersen LB, Anderssen SA, Quitério AL, Ornelas R, Froberg K, et al. Objectively measured time spent sedentary is associated with insulin resistance independent of overall and central body fat in 9- to 10-year-old Portuguese children. Diabetes Care. 2008;31(3):569-75.

13. Torres MD, Tormo MA, Campillo C, Carmona MI, Torres M, Reymundo M, et al. Etiologic and cardiovascular risk factors in obese children from Extremadura in Spain. Their relationship with insulin resistance and plasma adipocytokine levels. Rev Esp Cardiol. 2008;61(9):923-9.

14. Wells JC, Hallal PC, Reichert FF, Menezes AM, Araujo CL, Victora CG. Sleep patterns and television viewing in relation to obesity and blood pressure: evidence from an adolescent Brazilian birth cohort. Int J Obes (Lond). 2008;32(7):1042-9.

15. Martinez-Gomez D, Tucker J, Heelan KA, Welk GJ, Eisenmann JC. Associations between sedentary behavior and blood pressure in young children. Arch Pediatr Adolesc Med. 2009;163(8):724-30.

16. Hardy LL, Denney-Wilson E, Thrift AP, Okely AD, Baur LA. Screen time and metabolic risk factors among adolescents. Arch Pediatr Adolesc Med. 2010;164(7):643-9.

17. Kang HT, Lee HR, Shim JY, Shin YH, Park BJ, Lee YJ. Association between screen time and metabolic syndrome in children and adolescents in Korea: the 2005 Korean National Health and Nutrition Examination Survey. Diabetes Res Clin Pract. 2010;89(1):72-8.

18. Martinez-Gómez D, Eisenmann JC, Gómez-Martinez S, Veses A, Marcos A, Veiga OL. Sedentary behavior, adiposity and cardiovascular risk factors in adolescents. The AFINOS study. Rev Esp Cardiol. 2010;63(3):277-85.

19. McCrindle BW, Manlhiot C, Millar K, Gibson D, Stearne K, Kilty H, et al. Population trends toward increasing cardiovascular risk factors in Canadian adolescents. J Pediatr. 2010;157(5):837-43.

20. Rivera IR, Silva MA, Silva RD, Oliveira BA, Carvalho AC. Physical inactivity, TV-watching hours and body composition in children and adolescents. Arq Bras Cardiol. 2010;95(2):159-65.

21. Alvarez Caro F, Diaz Martín JJ, Riaño Galán I, Peréz Solís D, Venta Obaya R, Malaga Guerrero S. Classic and emergent cardiovascular risk factors in schoolchildren in Asturias. An Pediatr (Barc). 2011;74(6):388-95.

22. Carson V, Janssen I. Volume, patterns, and types of sedentary behavior and cardio-metabolic health in children and adolescents: a cross-sectional study. BMC Public Health. 2011;11:274

23. Danielsen YS, Juliusson PB, Nordhus IH, Kleiven M, Meltzer HM, Olsson SJ, et al. The relationship between life-style and cardio-metabolic risk indicators in children: the importance of screen time. Acta Paediatr. 2011;100(2):253-9.

24. Goldfield GS, Kenny GP, Hadjiyannakis S, Phillips P, Alberga AS, Saunders TJ, et al. Video game playing is independently associated with blood pressure and lipids in overweight and obese adolescents. PLoS One. 2011;6(11):e26643.

25. Hsu YW, Belcher BR, Ventura EE, Byrd-Williams CE, Weigensberg MJ, Davis JN, et al. Physical activity, sedentary behavior, and the metabolic syndrome in minority youth. Med Sci Sports Exerc. 2011;43(12):2307-13.

26. Lehto R, Ray C, Lahti-Koski M, Roos E. Health behaviors, waist circumference and waist-to-height ratio in children. Eur J Clin Nutr. 2011;65(7):841-8.

27. Altenburg TM, Hofsteenge GH, Weijs PJ, Delemarre-van de Waal HA, Chinapaw MJ. Self-reported screen time and cardiometabolic risk in obese Dutch adolescents. PLoS One. 2012;7(12):e53333.

28. Byun W, Dowda M, Pate RR. Associations between screen-based sedentary behavior and cardiovascular disease risk factors in Korean youth. J Korean Med Sci. 2012;27(4):388-94.

29. Martinez-Gómez D, Gomez-Martinez S, Ruiz JR, Ortega FB, Marcos A, Veiga OL. Video game playing time and cardiometabolic risk in adolescents: the AFINOS study. Med Clin (Barc). 2012;139(7):290-2.

30. Camhi SM, Waring ME, Sisson SB, Hayman LL, Must A. Physical activity and screen time in metabolically healthy obese phenotypes in adolescents and adults. J Obes. 2013;2013:984613.
31. Chaput JP, Saunders TJ, Mathieu ME, Henderson M, Tremblay MS, O'Loughlin J, et al. Combined associations between moderate to vigorous physical activity and sedentary behaviour with cardiometabolic risk factors in children. Appl Physiol Nutr Metab. 2013;38(5):477-83.

32. Colley RC, Garriguet D, Janssen I, Wong SL, Saunders TJ, Carson V, et al. The association between accelerometer-measured patterns of sedentary time and health risk in children and youth: results from the Canadian Health Measures Survey. BMC Public Health. 2013;13:200.

33. Govindan M, Gurm R, Mohan S, Kline-Rogers E, Corriveau N, Goldberg C, et al. Gender differences in physiologic markers and health behaviors associated with childhood obesity. Pediatrics. 2013;132(3):468-74

34. Rey-López JP, Bel-Serrat S, Santaliestra-Pasías A, de Moraes AC, Vicente-Rodríguez G, Ruiz JR, et al. Sedentary behaviour and clustered metabolic risk in adolescents: the HELENA study. Nutr Metab Cardiovasc Dis. 2013;23(10):1017-24.

35. Saunders TJ, Tremblay MS, Mathieu ME, Henderson M, O'Loughlin J, Tremblay A, et al. Associations of sedentary behavior, sedentary bouts and breaks in sedentary time with cardiometabolic risk in children with a family history of obesity. PLoS One. 2013;8(11):e79143

36. Sisson SB, Shay CM, Camhi SM, Short KR, Whited T. Sitting and cardiometabolic risk factors in U.S. adolescents. J Allied Health. 2013;42(4):236-42.

37. Stamatakis E, Coombs N, Jago R, Gama A, Mourao I, Nogueira H, et al. Type-specific screen time associations with cardiovascular risk markers in children. Am J Prev Med. 2013:44(5):481-8.

38. Berentzen NE, Smit HA, van Rossem L, Gehring U, Kerkhof M, Postma DS, et al. Screen time, adiposity and cardiometabolic markers: mediation by physical activity, not snacking, among 11-year-old children. Int J Obes (Lond). 2014;38(10):1317-23.

39. Chinapaw MJ, Altenburg TM, van Eijsden M, Gemke RJ, Vrijkotte TG. Screen time and cardiometabolic function in Dutch 5-6 year olds: cross-sectional analysis of the ABCD-study. BMC Public Health. 2014;14:933.

40. Cliff DP, Jones RA, Burrows TL, Morgan PJ, Collins CE, Baur LA, et al. Volumes and bouts of sedentary behavior and physical activity: associations with cardiometabolic health in obese children. Obesity (Silver Spring). 2014;22(5):E112-8.

41. Crispim PA, Peixoto Mdo R, Veiga Jardim PC. Risk factors associated with high blood pressure in two- to five-year-old children. Arq Bras Cardiol. 2014;102(1):39-46.

42. Flynn SE, Gurm R, DuRussel-Weston J, Aaronson S, Gakenheimer L, Smolarski J, et al. High-density lipoprotein cholesterol levels in middle-school children: association with cardiovascular risk factors and lifestyle behaviors. Pediatr Cardiol. 2014;35(3):507-13.

43. Vaisto J, Eloranta AM, Viitasalo A, Tompuri T, Lintu N, Karjalainen P, et al. Physical activity and sedentary behaviour in relation to cardiometabolic risk in children: cross-sectional findings from the Physical Activity and Nutrition in Children (PANIC) Study. Int J Behav Nutr Phys Act. 2014;11:55

44. do Prado Junior PP, de Faria FR, de Faria ER, Franceschini Sdo C, Priore SE. Cardiovascular Risk and Associated Factors in Adolescents. Nutr Hosp. 2015;32(2):897-904.

45. Herman KM, Sabiston CM, Mathieu ME, Tremblay A, Paradis G. Correlates of sedentary behaviour in 8- to 10-year-old children at elevated risk for obesity. Appl Physiol Nutr Metab. 2015;40(1):10-9.

46. Rendo-Urteaga T, de Moraes AC, Collese TS, Manios Y, Hagstromer M, Sjostrom M, et al. The combined effect of physical activity and sedentary behaviors on a clustered cardio-metabolic risk score: The Helena study. Int J Cardiol. 2015;186:186-95.

47. Robinson S, Daly RM, Ridgers ND, Salmon J. Screen-Based Behaviors of Children and Cardiovascular Risk Factors. J Pediatr. 2015;167(6):1239-45.

48. Safiri S, Kelishadi R, Qorbani M, Abbasi-Ghah-Ramanloo A, Motlagh ME, Ardalan G, et al. Screen time and its relation to cardiometabolic risk among children and adolescents: The CASPIAN-III study. Iranian Journal of Public Health. 2015;44(1):35-44.

49. Vaccaro JA, Huffman FG. Cardiovascular Endurance, Body Mass Index, Physical Activity, Screen Time, and Carotenoid Intake of Children: NHANES National Youth Fitness Survey. J Obes. 2016;2016:4897092.

50. Batalau R, Cruz J, Gonçalves R, Santos M, Leal J, Palmeira A. Project PANK: Rationale, study protocol and baseline results of a multidisciplinary school based intervention in children with cardiovascular and metabolic risk factors. Motriz: Rev Educ Fis. 2017;23(2).

51. Katzmarzyk PT, Staiano AE. Relationship Between Meeting 24-Hour Movement Guidelines and Cardiometabolic Risk Factors in Children. J Phys Act Health. 2017;14(10):779-84.

52. Norman GJ, Carlson JA, Patrick K, Kolodziejczyk JK, Godino JG, Huang J, et al. Sedentary Behavior and Cardiometabolic Health Associations in Obese 11-13-Year Olds. Child Obes. 2017;13(5):425-32

53. Hansen BH, Anderssen SA, Andersen LB, Hildebrand M, Kolle E, Steene-Johannessen J, et al. Cross-Sectional Associations of Reallocating Time Between Sedentary and Active Behaviours on Cardiometabolic Risk Factors in Young People: An International Children's Accelerometry Database (ICAD) Analysis. Sports Med. 2018;48(10):2401-12.

54. Cristi-Montero C, Chillon P, Labayen I, Casajus JA, Gonzalez-Gross M, Vanhelst J, et al. Cardiometabolic risk through an integrative classification combining physical activity and sedentary behavior in European adolescents: HELENA study. J Sport Health Sci. 2019;8(1):55-62.

55. de Moraes AC, Carvalho HB, Siani A, Barba G, Veidebaum T, Tornaritis M, et al. Incidence of high blood pressure in children - effects of physical activity and sedentary behaviors: the IDEFICS study: High blood pressure, lifestyle and children. Int J Cardiol. 2015;180:165-70.

56. Stamatakis E, Coombs N, Tiling K, Mattocks C, Cooper A, Hardy LL, et al. Sedentary time in late childhood and cardiometabolic risk in adolescence. Pediatrics. 2015;135(6):e1432-41.

57. Skrede T, Stavnsbo M, Aadland E, Aadland KN, Anderssen SA, Resaland GK, et al. Moderate-to-vigorous physical activity, but not sedentary time, predicts changes in cardiometabolic risk factors in 10-y-old children: the Active Smarter Kids Study. Am J Clin Nutr. 2017;105(6):1391-8. 
58. Vaisto J, Haapala EA, Viitasalo A, Schnurr TM, Kilpelainen TO, Karjalainen P, et al. Longitudinal associations of physical activity and sedentary time with cardiometabolic risk factors in children. Scand J Med Sci Sports. 2019;29(1):113-23.

59. Saunders TJ, Chaput JP, Goldfield GS, Colley RC, Kenny GP, Doucet E, et al. Prolonged sitting and markers of cardiometabolic disease risk in children and youth: a randomized crossover study. Metabolism. 2013;62(10):1423-8

60. Belcher BR, Berrigan D, Papachristopoulou A, Brady SM, Bernstein SB, Brychta RJ, et al. Effects of Interrupting Children's Sedentary Behaviors With Activity on Metabolic Function: A Randomized Trial. J Clin Endocrinol Metab. 2015;100(10):3735-43.

61. Lubans DR, Hesketh K, Cliff DP, Barnett LM, Salmon J, Dollman J, et al. A systematic review of the validity and reliability of sedentary behaviour measures used with children and adolescents. Obes Rev. 2011:12(10):781-99.

62. Shephard RJ. Limits to the measurement of habitual physical activity by questionnaires. Br J Sports Med. 2003;37(3):197-206

63. Cain KL, Sallis JF, Conway TL, Van Dyck D, Calhoon L. Using accelerometers in youth physical activity studies: a review of methods. J Phys Act Health. 2013;10(3):437-50.

64. Hamilton MT, Hamilton DG, Zderic TW. Exercise physiology versus inactivity physiology: an essential concept for understanding lipoprotein lipase regulation. Exerc Sport Sci Rev. 2004;32(4):161-6.

65. Pedersen BK, Febbraio MA. Muscles, exercise and obesity: skeletal muscle as a secretory organ. Nat Rev Endocrinol. 2012;8(8):457-65.

66. Chaput JP, Klingenberg L, Astrup A, Sjodin AM. Modern sedentary activities promote overconsumption of food in our current obesogenic environment. Obes Rev. 2011;12(5):e12-20.

67. Council On C, Media. Children, Adolescents, and the Media. Pediatrics. 2013;132(5):958-61.

68. Reid Chassiakos YL, Radesky J, Christakis D, Moreno MA, Cross C, Council On C, et al. Children and Adolescents and Digital Media. Pediatrics. 2016;138(5). pii:e20162593.

69. Caetano IT, Albuquerque MR, Nascimento FR, Mendes EL, Amorim PR. Análise do Comportamento Sedentário de Escolares por sexo, tipo de escola e turno escolar. Rev Bras Ci e Mov. 2016;24(1):16-26.

70. Felden EP, Filipin D, Barbosa DG, Andrade RD, Meyer C, Beltrame TS, et al. Adolescentes com sonolência diurna excessiva passam mais tempo em comportamento sedentário. Rev Bras Med Esporte. 2016;22(3):186-90.

71. Miranda VP, Dos Santos Amorim PR, Bastos RR, Souza VG, de Faria ER, do Carmo Castro Franceschini $\mathrm{S}$, et al. Evaluation of lifestyle of female adolescents through latent class analysis approach. BMC Public Health. 2019;19(1):184. 